\title{
Swollen Lymph Node
}

National Cancer Institute

\section{Source}

National Cancer Institute. Swollen Lymph Node. NCI Thesaurus. Code C50765.

The presence of an enlarged lymph node. 